\title{
Relationship between sexual harassment at workplace and subjective well- being among working women in South Punjab, Pakistan
}

\author{
Ahmad Bilal*1 $^{*} \mid$ Sehrish Wazir ${ }^{2} \mid$ Shakeela Altaf $^{1} \mid$ Samina Rasool ${ }^{1}$
}

1. Department of Applied Psychology, The Islamia University of Bahawalpur, Bahawalpur, Pakistan.

2. Department of Psychology, Government Sadiq College Women University, Bahawalpur, Pakistan.

*Correspondence Emails: ahmad.bilal@iub.edu.pk | ahmadbilal4@gmail.com

\begin{abstract}
Sexual Harassment at workplace (SHW) is a global phenomenon. However, there has been no prior research on the association of SHW and subjective well-being (SWB) of working women in Pakistan. The SWB is an umbrella term that encompasses concepts such as satisfaction with life (SWL) and subjective happiness $(\mathrm{SbH})$. The 200 working women from the public and private sector organizations in Pakistan were recruited randomly. The Sexual Harassment Experience Questionnaire, The Satisfaction with Life Scale, and Subjective Happiness Scale were administered as the main measures. The study met all the ethical considerations. The data was analyzed by the Statistical Package for the Social Sciences and expressed as baseline characteristics, correlation analysis and t tests. There was statistically significant negative relationship of SHW with SWL and SbH in working women. The young age, high school or less education, single marital status, and working in private sector organization were significantly associated with the increased and decreased experience of SHW and SWB respectively. The study recommended the adoption of anti SHW laws by the working sector and the periodic screening of working women for SWB so as to reduce the phenomenon of SHW and enhance the SWL and SbH in working women.
\end{abstract}

Article History

Received:

March 30, 2021

Last Revised:

May 30, 2021

Accepted:

June 18, 2021

Published:

June 30, 2021

Keywords: life satisfaction, sexual harassment, sexual harassment of women, sexual harassment at workplace, subjective happiness, subjective well-being, working women.

How to Cite: Bilal, A., Wazir, S., Altaf, S., \& Rasool, S. (2021). Relationship between sexual harassment at workplace and subjective well-being among working women in South Punjab. Liberal Arts and Social Sciences International Journal (LASSIJ), 5(1), 554-567. https://doi.org/10.47264/idea.lassij/5.1.36

Publisher's Note: IDEA PUBLISHERS (IDEA Journals Group) stands neutral with regard to the jurisdictional claims in the published maps and the institutional affiliations.

Copyright: () 2021 The Author(s), published by IDEA PUBLISHERS (IDEA Journals Group). This is an Open Access article published under the Creative Commons Attribution-NonCommercial 4.0 International License (http://creativecommons.org/licenses/by-nc/4.0/) 


\section{Introduction}

Sexual harassment at Workplace (SHW) is a popular form of sexual harassment ( $\mathrm{SH}$ ) and takes many forms. Popularly, the phenomenon of SH is known as Eve Teasing in South Asian countries especially India (Salman et al., 2016). Every state defines SHW differently but the common characteristic is the unwanted advancement of sexual nature (Matsumoto \& Juang, 2013). The UN defines SHW as any behavior that inhibits work performance and creates a hostile work environment for women (UN Women, 2013). The women are usually the victims of SHW and men are usually the perpetrators (Espelage et al., 2016; Gruber \& Fineran, 2016). Traditionally, the eves are considered responsible to tempt the men in harassing them (Hoque, 2013; Kuruvilla \& Suhara, 2014).

Recently, the focus in studying the impact of SH on women's wellbeing is increased among researchers and policy makers (Mitchell et al., 2014). Previously, the phenomenon of SHW has been mainly studied in the context of job satisfaction and other related organizational outcomes (McDonald et al., 2015; Mellor \& Golay, 2014). Most of these studies had been conducted in USA, UK, Australia and other EU countries but little studies have been conducted in Pakistan (Ali \& Kramer, 2015). The studies conducted in western nations cannot be generalized to Pakistan because of differences in gender roles and concepts about women modesty (Ali, 2013). There is not a single study conducted with Pakistani working women on the relationship of SHW and SWB. The study was conducted to fill this gap. The present study tried to find out a relationship between SHW and SWL and $\mathrm{SbH}$ in working women. Additionally, the study aimed at finding out the socio demographic determinants of SHW and SWB in the working women. The study also tried to uncover the association of SHW with age group, education, marital status, and the working sector type among the working women of South Punjab.

\section{Review of literature}

The phenomenon of SHW is associated with certain socio psychological consequences of longterm nature such as losing one's self esteem (Ahmad et al., 2020; Muazzam et al., 2016). The SHW results in decreased job satisfaction and is positively associated with psychological distress which further leads to decreased psychological well-being (Hashmi et al., 2013) and decreased overall happiness in working women (Quick \& McFadyen, 2017).

Mitchell et al. (2014) describes the phenomenon as unwanted requests and favors, gestures, and comments of sexual nature. The SH can be categorized into three types based on classic tripartite model of typology of SH (Fitzgerald et al., 1997), (a) gender harassment which includes verbal or nonverbal sexist comments about the other gender; (b) unwanted sexual attention behaviors; and (c) sexual coercion when workplace rights are conditioned with fulfillment of men's sexual demands (NASEM, 2018). The third type is less common of all these yet is associated with greater amounts of decreased psychological well-being (Sojo et al., 2016; Thurston et al., 2017). These SH types are consistent across cultures and organizations (Holland \& Cortina, 2016). Often, a distinction among these types is not made. That's why, the gender harassment is not often considered a type of $\mathrm{SH}$ whereas the gender type of $\mathrm{SH}$ is the most common type.

The SH can occur in any form like kissing, pinching, touching, leering, embracing or patting. The more subtle forms of SH are stalking, unwanted emails, dirty jokes, or questions about a 
woman's personal or sexual life. The women are more likely to be victims of SH as compared to men (Chiodo et al., 2009) because of unequal gender roles and status in society (Clair et al., 2019). Similarly, the act of gaining sexual consent of the women by threat, fear or coercion is also considered an act of SHW (Aloka, 2009). There are several reasons of SHW against women. Foremost is the patriarchal structure of Pakistani society (Akhtar \& Métraux, 2013) where traditional gender roles prevail and mixing of genders is considered a bad practice (Sigal et al., 2005). The women in Pakistan are expected to keep traditional coy and honor of their patriarchal family members (Yasmin \& Jabeen, 2017). Therefore, men having patriarchal ideas misinterpret the working of women outside of home and consider it legitimate to sexually harass the women at workplace (Mangi, 2011).

The men use SH as a tool to show their masculinity (Mikorski \& Syzmanski, 2017) and the phenomenon is considered to be a type of entertainment for men (Dhillon \& Bakaya, 2014) and as a way to let off their sexual frustrations (Farooqi \& Hajani, 2017). Generally, it is believed that women provocate men to sexually harass them and they enjoy the act (Kuruvilla \& Suhara, 2014). It is often advised to women to keep distance from their male colleagues and keep a stern look while working with them. The act of SH of women are laughed off in most Pakistani families, thus helping this menace to maintain (Akhtar, 2013). There are environment based organizational characteristics, which increase the chances of incidents of SHW against women. These include greater ratios of men in the organization, the male leadership, and organizations that tolerate the incidents of SHW (Quick \& McFadyen, 2017; NASEM, 2018). The organization's tolerance of harassing behavior is the biggest factor that leads to more incidents of SHW.

The terms satisfaction with life (SWL) and subjective happiness ( $\mathrm{SbH}$ ) are often used interchangeably but they are two distinct and separate concepts (Anand, 2016). Both of these concepts are often encompassed by the term subjective well-being (SWB). The satisfaction with life is the evaluation of one's life at any given time according to famous researcher Ed Diener (Beutell, 2006). Satisfaction with Life is a broader and stable concept and refers to one's general evaluation of one's life quality. On the other hand, the term happiness, often synonymous with $\mathrm{SbH}$, is one of several constructs that make a person satisfied with his/her life. Usually, happiness alone is not enough to make one's life satisfied. Lyubomirsky (2001) defines happiness as a feeling of joy, and contentment and positive well-being coupled with a sense that life is good, meaningful and worthwhile. Happiness is a feeling of enduring satisfaction and contentment in life (Mohanty, 2014). Both, SWL and SbH are interdependent and mutual to each other (Veenhoven, 2004).

The more broader term SWB is used to refer to one's affective and cognitive evaluations about the well-being (Diener et al., 2002). There are three components of SWB. These are: (a) the presence of positive affect; (b) the absence of negative affect; and (c) the SWL, making it the tripartite model of SWB (Lee et al., 2013; Busseri \& Sadava, 2011; Tov \& Diener, 2013). The first two components are emotional in nature and a balance between these two components is considered to promote $\mathrm{SbH}$. The third component is the cognitive evaluation of one's SWL. Often, the sources and determinants of both SWL and $\mathrm{SbH}$ are same for the people (Tsuladze et al., 2013).

The SHW is a commonly prevalent phenomenon globally. Even, it is hard to find a woman who has not been victim of SH of any kind in her lifetime (Akhtar, 2013; Dhillon \& Bakaya, 2014). Similarly, in Pakistan, SHW had been reported in working women employed in urban 
banking sectors (Nauman \& Abbasi, 2014) although, the participation of women in Pakistani workplaces is increasing and there are many women friendly occupations in Pakistan now (Zia et al., 2016). Despite the increasing number of women participation in workforce of Pakistan, there is an alarmingly huge proportion of women (93\%) that become the victim of SHW either in public or private sector (SPDC, 2009). Several incidents of SH against women occur on daily basis (Farooqi \& Hajani, 2017). A report by Reuters Foundation ranks Pakistan as the sixth bad state after Saudi Arabia and Somalia when it comes to SH against women (Reuters, 2018). Previously, Pakistan had been a dangerous and insecure place for women (Akhtar \& Métraux 2013) because of frequent incidences of SH against women. Some other studies using convenient sampling in other parts of the world reported prevalence of $\mathrm{SH}$ as ranging from $50 \%$ to $70 \%$ (Feldblum \& Lipnic, 2016).

Although, Pakistan has introduced Protection against Harassment of Women at Workplace Act (PAHWWA) in 2010 (NAP, 2010) to punish those stalking women, but the government has done little to implement the laws related to SHW (Akhtar \& Métraux 2013; Nosheen, 2011; Qureshi, 2013). That is why, women are still reluctant to report incidents of SHW and seek help (Yasmin, 2018). The patriarchal culture of Pakistan is a major hurdle in making women reluctant of reporting incidents of SHW where such women are considered a shame to the family thus, they prefer to keep silent (Akhtar \& Métraux 2013; Ali, 2010; Hadi, 2017; Shams, 2018). In cultures like Pakistan, the women are trained to remain silent from the very early age when experience SH (Muazzam et al., 2016) and accept SH as a routine fact of their lives (Kamal, 2005). Spencer et al. (2017) reported that women who experience incidents of SH become so sensitive that they fail to report these incidents to others. It is usually silence about the SH that helps promote the phenomena (Dey, 2013) as in Pakistan, women are often advised to keep silent about the incidence of SH whereas in US, women are encouraged to take photo of perpetrator to be produced before police (Ramezani, 2015).

On the other hand, those working women who take up some courage and discuss the issue of SH receive negative responses from their family members and unsatisfactory response from higher legal authorities. (Yasmin, 2018) even the police suppress and harass the woman who reports such matters (Abbas, 2011; Mustafa, 2017), though the "Me too" movement has penetrated little in Pakistani society (Ahmad et al., 2020), yet, the culture of Pakistani society is traditionally indoctrinated to remain silent about issue of SH against women (Muazzam et al., 2016).

\section{Research methodology}

\subsection{Research design}

The cross sectional and survey research design was employed in this research.

\subsection{Participants}

A total of 200 working women were randomly recruited from the public and private sector organizations including civil and military hospitals, banks, radio stations, business organizations, textile industries, shopping malls, private transportation companies, railways, mobile service providers' franchises, police department, courts, and educational institutions. The sample was recruited by the team of researchers using systematic random sampling based on the number of working women in the organization. These women ranged from lower rank 
workers to officers' rank in the age range of 18-42 years. They were recruited from the districts of Bahawalpur, Rahim Yar Khan, Multan, Lodhran, Muzafargarh and Dera Ghazi Khan in South Punjab.

\subsection{Inclusion and exclusion criteria}

Only working women from the South Punjab who belonged to age range 18-42 years were included in the sample. The working women from South Punjab were included in the sample because little work had been done on the relationship of SHW and other psychological variables. The housewives, women below 18 years of age or above 42 years of age and those from other states and provinces were excluded from the sample.

\subsection{Measures}

\subsubsection{Demographic Information Checklist (DIC)}

A demographic information checklist was constructed by the researchers. It included basic demographic information like age, education, marital status, working sector, and city of the participating women.

\subsubsection{Sexual Harassment Experience Questionnaire (SHEQ)}

The Sexual Harassment Experience Questionnaire (SHEQ) is a standardized self-report measure to assess the experiences of SHW. It contains 35 items that ask the respondents about their SH experiences on a 4-point Likert type scale. The four Likert type response categories are never (1), Once (2), A few times (3), and very frequent (4). The scale score has been obtained by the total sum of the responses on all items. The higher scores represent a higher level of SH. The Cronbach Alpha reliability of Pakistani standardized SHEQ is 0.94 (Kamal \& Tariq, 1997).

\subsubsection{Satisfaction with Life Scale (SWLS)}

The Satisfaction with Life Scale (SWLS) was developed by Diener (1985) which consists of 5 items designed to measure overall life satisfaction. It is 7 Point Likert type scale and the response categories range from strongly disagree (1) to strongly agree (7). The total score is obtained by the sum of score of each item. The higher score represents higher level of SWL. The Cronbach Alpha reliability of the scale is 0.87 whereas the test-retest reliability of the scale is 0.82 (Diener et al., 1985). The Cronbach Alpha reliability of the scale was 0.81 for the Urdu translated version.

\subsubsection{Subjective Happiness Scale (SHS)}

The Subjective Happiness Scale was developed by Lyubomirsky and Lepper in 1999 which consists of 4 items designed to assess general happiness on a 7 Point Likert type scale. The Likert type response items vary from not at all (1) to a great deal (7). The total score is the sum of responses on all items. The greater scores represent greater level of $\mathrm{SbH}$. The Cronbach Alpha reliability of the scale is 0.86 (Lyubomirsky \& Lepper, 1999). The Cronbach Alpha reliability of the scale was 0.89 for the Urdu translated version. 


\subsubsection{Procedure}

The ethical approval was obtained from the research ethics committee of department of Applied Psychology at The Islamia University of Bahawalpur, Pakistan. The written permission was obtained for data collection by the organizational heads. The researchers developed Informed Consent Form (ICF) and DIC and finalized the measures. The researchers conducted a pilot study for standardization of the two scales, SWLS and SHS in Urdu language using back translation method. The data of the pilot study was not included in the final statistical analysis. The data was collected by administering the measures to the participating women. The written informed consent was obtained and all the ethical information and research participation protocols were explained to participating women before enrolling them in the study. The working women from the participating organizations were recruited by using systematic random sampling to fill up the questionnaires.

\subsubsection{Ethical considerations}

The study met all the ethical considerations. The nature and purpose of the study including possible harms was explained to all participants and written informed consent was obtained from all the participants before enrolling them in the study. They were told that the data obtained from them will only be used for research and will be kept confidential.

\subsubsection{Statistical analysis}

The data was analyzed by the Statistical Package for the Social Sciences (IBM, USA) version 25. The results were expressed in the form of baseline characteristics of participants, a correlation between the SHW, SWL and SbH, and several $t$ tests for finding socio demographic determinants of SHW and SWB. The Cohen's d was also calculated for t tests. The 0.2, 0.5, and 0.8 were considered small, medium and large effect sizes respectively (Cohen, 1977). The correlation was two tailed and was significant at $99 \%$ confidence interval.

\subsubsection{Limitations}

The limitations of the study are as follows:

- The study data is restricted to South Punjab only, hence, the findings can not be generalized to whole Punjab.

- The study did not include the demographic variable of rank of the women in the organization.

- The study did not assess other important and related psychological parameters like psychological distress, absenteeism, depression, helplessness, and suicidal ideation as a possible outcome of effects of SHW.

\section{Results and analysis}

\subsection{Baseline characteristics of participants}

The baseline characteristics of the participants are outlined in Table-1. The ( $n=200)$ working women participated in the study. Their age range was $18-42$ years $(M=26$ years; $S D=5.20)$. 
There were $73.5 \%$ working women in the early adulthood age range (18-29 years) whereas $26.5 \%$ working women were in the middle adulthood age range (30-42 years). Majority have passed senior high school exam or more education (83\%) compared with the $17 \%$ who only had passed high school exam or less education. The 52\% women were single whereas $48 \%$ were married. There were slightly more women working in the private sector $(51 \%)$ compared with $49 \%$ who were working in the public sector organizations.

Table-1: Socio demographic characteristics of participants at baseline $(\mathrm{N}=200)$

\begin{tabular}{llll}
\hline Socio Demographic Variables & Baseline Characteristics & $\mathrm{N}$ & $\%$ \\
\hline Age & $18-29$ years & 147 & 73.5 \\
& $30-42$ years & 53 & 26.5 \\
& Total & 200 & 100.0 \\
\hline Education & High School or Less & 34 & 17.0 \\
& Senior High School or Above & 166 & 83.0 \\
& Total & 200 & 100.0 \\
\hline Marital Status & Single & 104 & 52.0 \\
& Married & 96 & 48.0 \\
& Total & 200 & 100.0 \\
\hline Organizational Type & Public Sector & 98 & 49.0 \\
& Private Sector & 102 & 51.0 \\
& Total & 200 & 100.0 \\
\hline
\end{tabular}

\subsection{Correlation analysis}

The Table-2 shows the results of correlation analysis of SHW with SWL and SbH. The study variables SHW and SWB (SWL and SbH) showed a statistically significant correlation among them. The SHW is negatively correlated with both SWL $(\mathrm{r}(198)=-0.72, p<0.01)$ and $\mathrm{SbH}(\mathrm{r}$ $(198)=-0.57, p<0.01)$. The SWL is positively correlated with SbH in working women ( $\mathrm{r}(198)$ $=0.68, p<0.01)$.

Table-2: Descriptive statistics and correlations among SHW, SWL and $\mathrm{SbH}(\mathrm{N}=200)$

\begin{tabular}{lllllll}
\hline Variables & N & M & SD & 1 & 2 & 3 \\
\hline Sexual Harassment & 200 & 81.16 & 26.01 & - & & \\
Satisfaction with Life & 200 & 16.86 & 8.50 & $-0.72^{* *}$ & - & \\
Subjective Happiness & 200 & 14.22 & 6.46 & $-0.57^{* *}$ & $0.68^{* *}$ & - \\
\hline
\end{tabular}

**p $<0.01$

\section{3. $\quad t$ tests}

The Table- 3 gives the results of several $t$ tests computed to find the group differences in the socio demographic variables of age, education, marital status, and working sector type for SHW, SWL and SbH. The working women in the early adult years $(\mathrm{M}=85.76 ; \mathrm{SD}=26.62)$, with high school or less education $(\mathrm{M}=94.21$; $\mathrm{SD}=25.89)$, having single marital status $(\mathrm{M}=$ 89.61; $\mathrm{SD}=27.54)$ and working in a private sector organization $(\mathrm{M}=94.08 ; \mathrm{SD}=26.26)$ had been victim of SHW as compared to women in middle ages $(\mathrm{M}=68.40 ; \mathrm{SD}=19.33)$, having senior high school or above education $(\mathrm{M}=78.48$; $\mathrm{SD}=25.29)$, having married status $(\mathrm{M}=$ $72.0 ; \mathrm{SD}=20.78)$ or working in a public sector organization $(\mathrm{M}=67.70 ; \mathrm{SD}=17.65)$ respectively $(t(126.32)=5.03, p=0.000$, Cohen's $d=0.74) ;(t(198)=-3.28, p=0.001$, Cohen's 
$\mathrm{d}=0.61) ;(t(190.62)=-5.12, p=0.000$, Cohen's $\mathrm{d}=0.72)$; and $(t(177.47)=-8.36, p=0.000$, Cohen's $d=1.17)$.

Table-3: Results of several $t$ tests $(\mathrm{N}=200)$

\begin{tabular}{|c|c|c|c|c|c|c|c|}
\hline Age & \multicolumn{2}{|c|}{$18-29 y(n=147)$} & \multicolumn{5}{|c|}{$30-42 y(n=53)$} \\
\hline Variables & $\mathrm{M}$ & SD & $\mathrm{M}$ & SD & $t(\mathrm{df})$ & $p$ & Cohen's d \\
\hline SHW & 85.76 & 26.62 & 68.40 & 19.33 & $5.03(126.32)$ & .000 & 0.74 \\
\hline SWL & 15.25 & 8.18 & 21.30 & 7.81 & $-4.66(198)$ & .000 & 0.75 \\
\hline $\mathrm{SbH}$ & 13.35 & 6.35 & 16.64 & 6.19 & $-3.25(198)$ & .001 & 0.52 \\
\hline Education & \multicolumn{2}{|c|}{$\leq 10^{\text {th }} \mathrm{G}(\mathrm{n}=34)$} & \multicolumn{5}{|c|}{$\geq 12^{\text {th }} \mathrm{G}(\mathrm{n}=166)$} \\
\hline Variables & M & SD & $\mathrm{M}$ & SD & $t(\mathrm{df})$ & $p$ & Cohen's d \\
\hline SHW & 94.21 & 25.89 & 78.48 & 25.29 & $-3.28(198)$ & .001 & 0.61 \\
\hline SWL & 12.18 & 7.32 & 17.81 & 8.42 & $3.62(198)$ & .000 & 0.71 \\
\hline $\mathrm{SbH}$ & 11.68 & 5.79 & 14.74 & 6.48 & $2.55(198)$ & .011 & 0.49 \\
\hline Marital Status & \multicolumn{2}{|c|}{ Single $(n=104)$} & \multicolumn{5}{|c|}{ Married $(n=96)$} \\
\hline Variables & M & SD & $\mathrm{M}$ & SD & $t(\mathrm{df})$ & $p$ & Cohen's d \\
\hline SHW & 89.61 & 27.54 & 72.00 & 20.78 & $-5.12(190.62)$ & .000 & 0.72 \\
\hline SWL & 14.00 & 8.15 & 19.95 & 7.79 & $5.26(198)$ & .000 & 0.74 \\
\hline $\mathrm{SbH}$ & 12.48 & 6.18 & 16.10 & 6.25 & 4.11(198) & .000 & 0.58 \\
\hline $\begin{array}{l}\text { Working Sector } \\
\text { Type }\end{array}$ & \multicolumn{2}{|c|}{ Public $(n=98)$} & \multicolumn{5}{|c|}{ Private $(n=102)$} \\
\hline Variables & $\mathrm{M}$ & SD & $\mathrm{M}$ & SD & $t(\mathrm{df})$ & $p$ & Cohen's d \\
\hline SHW & 67.70 & 17.65 & 94.08 & 26.26 & $-8.36(177.47)$ & .000 & 1.17 \\
\hline SWL & 21.41 & 6.87 & 12.48 & 7.59 & $8.70(198)$ & .000 & 1.23 \\
\hline $\mathrm{SbH}$ & 17.42 & 5.45 & 11.15 & 5.85 & 7.83(198) & .000 & 1.10 \\
\hline
\end{tabular}

\section{Discussion and findings}

The study found a statistically significant relationship among SHW, SWL and SbH in working women. Both the SWL and SbH were found to be negatively associated with phenomenon of SHW. As the two constructs ( $\mathrm{SWL}$ and $\mathrm{SbH}$ ) are always positively correlated with each other as also reported by this study, it is no wonder that both of these vary in the same direction due to the impact of SH (Table $2 \& 3$ ). The previous studies also documented that SHW was negatively correlated with both SWL and SbH in working women (Quick \& McFadyen, 2017; Hashmi et al., 2013).

The age group of the working women is a strong predictor of who will be receiving more SHW (Nauman \& Abbasi, 2014). The women in early adult years (18-29 years) were found to be victim of SHW more than those women who are in their middle age years (30-42 years). One reason of this association is that women in their young age are more physically attractive. Being physically attractive has been mentioned as a reason of SHW by an earlier study conducted with Pakistani women bankers (Nauman \& Abbasi, 2014). Another reason is the biological evolutionary theory which states that the men chase women as they try to maximize their genes (Diehl et al., 2018). When the women do not accept their advances, they are labelled as committing the act of SH. The evolutionary biological theory has received little research support (Page \& Pina, 2015).

The educational background of working women is an important determinant of SHW experience. The current study found that those women received more SHW who had only obtained high school or less education as compared to those women who had obtained senior 
high school or above education. Education equips the women with knowledge and skills that help them cope with SHW attempts. The less educated women become an easy prey for those men who try to sexually harass women at workplace. Another reason is that the women with high school or less education are often ranked low in an organization which increases their chances of experiencing SHW (Nauman \& Abbasi, 2014; Sadruddin, 2013).

An interesting finding of this study is that single women received more SHW as compared to married women. Usually, the single women are considered more attractive, and considered looking for an opposite sex relationship. In Pakistani society, the single women are usually into their mid to late 20s, a time marked with more attractiveness in Pakistani society. Being single when combined with being in the early adult years becomes the perfect combination to become a victim of SHW as is reported by this study and is consistent with the previous studies as well (Diehl et al., 2018; Nauman \& Abbasi, 2014).

The working sector of an organization like a public sector or private sector makes its women employees more vulnerable to SHW. This study found that women working in private sector organizations experience SHW more as compared to public sector organizations. This difference may be attributed to the working environment of the organization, its location, the number of other female members and gender of supervisor. The small or medium sized private organizations barely adopt the government's policies against SHW and provide enough securities against such practices, hence, such organizations become hotspot of SHW incidents. The previous studies in Pakistan confirm this finding (Sadruddin, 2013; Abbas \& Ashiq, 2020).

\section{Conclusion}

The study concludes that SHW has serious implications for the SWB of working women and is negatively correlated with both SWL and SbH. The presence of SHW was found to be associated with low levels of both SWL and SbH in working women. The demographic characteristics such as young age, having secondary school or less education, being single, and working in a private organization were associated with the experience of SHW. On the other hand, middle age, having higher secondary school or less education, being married, and working in a public sector organization were associated with more SWL and $\mathrm{SbH}$ and less chances of SHW. The future studies may be conducted with other demographic variables as well such as the rank or position of working women in the organization. Moreover, future studies need to assess psychological and work related aspects of working women such as mental distress, depression, hopelessness, absenteeism, and turnover intention as an outcome of effects of SHW. The study recommended that every organization should have an anti SH cell which should devise effective policies to minimize the incidents of SHW in the light of available research. Recommendations of the study are as follows:

- Every organization should impart regular trainings to its employees to raise awareness against the SHW. Small group workshops can be conducted at regular intervals for creating awareness.

- Every organization should create an atmosphere for its women employees where they may work safely and do not experience SHW.

- Every organization should have the services of a qualified organizational or counseling psychologist for the timely counseling of victimized women and for doing the timely assessment of their current levels of SWB. 


\section{Acknowledgments}

We acknowledge the original contribution of the participating women from the different organizations. Without their participation, the present research had not been possible. We also like to acknowledge the support of the management of different organizations in South Punjab, Pakistan for allowing us to collect data from their women employees.

\section{Conflict of interest}

The authors declare no conflict of interest.

\section{Funding}

The authors received no funding for conducting or publishing this research.

\section{References}

Abbas, H. (2011). Reforming Pakistan's police and law enforcement infrastructure. US Institute of Peace, Washington. https://www.jstor.org/stable/pdf/resrep12443.pdf

Abbas, N. \& Ashiq, U. (2020). Why I don't Blow the Whistle? Perceived Barriers by the University Teachers to Report Wrong Doings. Liberal Arts and Social Sciences International Journal (LASSIJ), 4 84-97. https://doi.org/10.47264/idea.lassij/4.2.8

Ahmad, N. M., Ahmad, M. M., \& Masood, R. (2020). Socio psychological Implications of Public Harassment for Women in the Capital City of Islamabad. Indian Journal of Gender Studies, 27 (1), 77-100. http//doi.org/10.1177/0971521519891480

Akhtar, C. (2013). Eve teasing as a form of violence against women: A case study of District Srinagar, Kashmir. International Journal of Sociology and Anthropology, 5 (5), 168-178. https://doi.org/10.5897/IJSA2013.0445

Akhtar, N., \& Metraux, D. A. (2013). Pakistan is a dangerous and insecure place for women. International Journal of World Peace, 30 (2), 35-70. https://www.proquest.com/openview/f9de78b2257149b21cc8f86ddcb626cb/1?pqorigsite $=$ gscholar \&cbl $=30293$

Ali, F. (2013). A multi-level perspective on equal employment opportunity for women in Pakistan. Equality, Diversity and Inclusion, 32 (3), 289-309. https://doi.org/10.1108/EDI-12-2012-0110

Ali, F. (2010). Sexual harassment in Pakistan: An invisible crime. SEPLAA News. http://www.seplaafoundation.org/index.php/2011/01/sexualharassmentin-pakistanan-invisible-crime/

Ali, F., \& Kramar, R. (2015). An exploratory study of sexual harassment in Pakistani organizations. Asia Pacific Journal of Management, 32 (1), 229-249. https://doi.org/10.1007/s10490-014-9380-1

Aloka, J. (2009). Prevalence and management of sexual harassment at the workplace: The case of Uganda Prison Service. Doctoral dissertation, Makerere University. https://www.mak.ac.ug/documents/Makfiles/theses/Aloka_Julias.pdf

Anand, P. (2016). Happiness explained: What human flourishing is and what we can do to promote it. Oxford University. 
Beutell, N. J. (2006). Life satisfaction in relation to work and family. Unpublished paper. https://www.researchgate.net/publication/259486067_Life_Satisfaction_in_Relation to Work_and Family

Busseri, M. A., \& Sadava, S. W. (2011). A review of the tripartite structure of subjective wellbeing: implications for conceptualization, operationalization, analysis, and synthesis. Personality and Social Psychology Review, 15 (3), 290-314. https://doi.org/10.1177/1088868310391271

Chiodo, D., Wolfe, D. A., Crooks, C., Hughes, R., \& Jaffe, P. (2009). Impact of sexual harassment victimization by peers on subsequent adolescent victimization and adjustment: A longitudinal study. Journal of Adolescent Health, 45 (3), 246-252. https://doi.org/10.1016/j.jadohealth.2009.01.006

Clair, R. P., Brown, N. E., Dougherty, D. S., Delemeester, H. K., Geist-Martin, P., Gorden, W. I., Sorg, T., \& Turner, P. K. (2019). \#MeToo, sexual harassment: an article, a forum, and a dream for the future. Journal of Applied Communication Research, 47 (2), 111 129. http://doi.org/10.1080/00909882.2019.1567142

Cohen, J. (1977). Statistical power analysis for the behavioral sciences (Rev. ed.). Lawrence Erlbaum Associates.

Dey, P. (2013). Sexual harassment at workplace-An empirical study to understand through the lenses of working women of Guwahati, Assam, India. IOSR Journal of Humanities and Social Science, 8(6), 77-82. https://doi.org/10.9790/0837-0867782

Dhillon, M., \& Bakaya, S. (2014). Street harassment: A qualitative study of the experiences of young women in Delhi. SAGE Open, 4 (3), 1-11. https://doi.org/10.1177/2158244014543786

Diehl, C., Rees, J., \& Bohner, G. (2018). Predicting sexual harassment from hostile sexism and short-term mating orientation: Relative strength of predictors depends on situational priming of power versus sex. Violence Against Women, 24(2), 123-143. https://doi.org/10.1177\%2F1077801216678092

Diener, E., Oishi, S., Lucas, R. E. (2002). Subjective well-being: The science of happiness and life satisfaction. Handbook of Positive Psychology. Oxford University.

Diener, E., Emmons, R. A., Larsen, R. J., Griffin, S. (1985). The satisfaction with life scale. Journal of Personality Assessment, $49 \quad$ (1), 71-75. https://doi.org/10.1207/s15327752jpa4901_13

Espelage, D. L., Hong, J. S., Rinehart, S., \& Doshi, N. (2016). Understanding types, locations, \& perpetrators of peer-to-peer sexual harassment in US middle schools: A focus on sex, racial, and grade differences. Children and Youth Services review, 71, 174-183. http://doi.org/10.1016/j.childyouth.2016.11.010

Farooqi, H., \& Hajani, K. (2017, April 28). It's her fault: Gendered mobility, space and risk University of Karachi. Paper presented at Institute of Business Administration, Lahore University of Management Sciences (LUMS). https://swgi.lums. edu.pk/sites/default/files/user376/publication_of_abstracts_2017.pdf

Feldblum, C. R., \& Lipnic, V. A. (2016, June). Select task force on the study of harassment in the workplace. https://www.gov/eeoc/task_force/harassment/upload/report.pdf

Fitzgerald, L. F., Swan, S., \& Magley, V. J. (1997). But was it really sexual harassment? Legal, behavioral, and psychological definitions of the workplace victimization of women. In W. O'Donohue (Ed.), Sexual harassment: Theory, research, and treatment (pp. 528). Allyn \& Bacon.

Gruber, J., \& Fineran, S. (2016). Sexual harassment, bullying, and school outcomes for high school girls and boys. Violence Against Women, 22(1), 112-133. http://doi.org/10.1177/1077801215599079 
Hadi, A. (2017). Patriarchy and gender-based violence in Pakistan. European Journal of Social Science Education and Research, 4(4), 297-304. http://journals.euser.org/index.php/ejser/article/view/2485

Hashmi, A., Rehman, A., Butt, Z., Aftab, M., Shahid, A., Khan, S. (2013). Gender discrimination among medical students in Pakistan: a cross sectional survey. Pakistan Journal of Medical Sciences, 29 (2), 449-453. http://doi.org/10.12669/pjms.292.3256

Holland, K. J., \& Cortina, L. M. (2016). Sexual harassment: Undermining the well-being of working women. In M. L. Connerley \& J. Wu (Eds.), Handbook on well-being of working women (pp. 83-101). Springer.

Hoque, M. (2013). Eve teasing in Bangladesh: Causes and impact on society, a study from Islamic perspective. International Journal of Social Sciences, 15(1), 1-11.

Kamal, A. (2005). Relationship between gender role attitudes of attribution of responsibility for sexual harassment responsibility for sexual harassment among university students. Personality study and group behavior, 25, 9-18.

Kuruvilla, M., \& Suhara, F. (2014). Response patterns of girl students to eve teasing: An empirical study in a University setting. International Journal of Education and Psychological Research (IJEPR), 3 (3), 60-64.

Lee, Y. C., Lin, Y. C., Huang, C. L., \& Fredrickson, B. L. (2013). The construct and measurement of peace of mind. Journal of Happiness Studies, 14 (2), 571-590. https://doi.org/10.1007/s10902-012-9343-5

Lyubomirsky, S. (2001). Why are some people happier than others? The role of cognitive and motivational processes in well-being. American Psychologist, 56(3), 239-249. http://doi.org/10.1037/0003-066X.56.3.239

Lyubomirsky, S., \& Lepper, H. S. (1999). A measure of subjective happiness: Preliminary reliability and construct validation. Social Indicators Research, 46 (2), 137-155. https://doi.org/10.1023/A:1006824100041

Mangi, N. (2011). Convoys and patdowns: A day at the office in Pakistan. Bloomberg Businessweek, 42 (39), 11-13.

Matsumoto, D. R., \& Juang, L. P. (2013). Culture and psychology. Wadsworth.

McDonald, P., Charlesworth, S., \& Graham, T. (2015). Developing a framework of effective prevention and response strategies in workplace sexual harassment. Asia Pacific Journal of Human Resources (APJHR), 53(1), 41-58. http://doi.org/10.1111/1744$\underline{7941.12046}$

Mellor, S. \& Golay, L.M. (2014). The conditional indirect effect model of women's union Participation: The moderating effect of perceived union tolerance for sexual harassment. The Journal of Psychology: Interdisciplinary and Applied, 148 (1), 73 91. https://doi.org/10.1080/00223980.2012.748580

Mikorski, R., \& Szymanski, D. M. (2017). Masculine norms, peer group, pornography, Facebook, and men's sexual objectification of women. Psychology of Men \& Masculinity, 18(4), 257-267. http://doi.org/10.1037/men00005

Mitchell, K. J., Ybarra, M. L., \& Korchmaros, J. D. (2014). Sexual harassment among adolescents of different sexual orientations and gender identities. Child Abuse \& Neglect, 38(2), 280-295. https://doi.org/10.1016/j.chiabu.2013.09.008

Mohanty, M. S. (2014). What determines happiness? income or attitude: Evidence from the US longitudinal data. Journal of Neuroscience, Psychology, \& Economics, 7(2), 80-102. http://doi.org/10.1037/npe0000019

Muazzam, A., Qayyum, F. \& Cheng, J. (2016). Experiences of sexual harassment: Interplay of working environment, depression and self-esteem in Pakistani women. Pakistan Journal of Social and Clinical Psychology, 14(1), 42-46. 
Mustafa, W. (2017, January 6). Pakistani province launches app for women to report harassment. Reuters. https://www.reuters.com/article/ us-pakistan-women-app/pakistani-province-launches-app-for-women-toreportharassment-idUSKBN14P2B7

National Academies of Sciences, Engineering, and Medicine (NASEM) (2018, June 12). Sexual harassment of women: Climate, culture, and consequences in academic sciences, engineering, and medicine. The National Academies Press. http://doi.org/10.17226/24994

National Assembly of Pakistan (NAP) (2010, March 9). The protection against harassment of women at the workplace act. http://www.na.gov.pk/en/acts-tenure.php?tenure_id=1

Nosheen, H. (2011). Violence against women. Dialogue, 6 (3), 290-299.

Nauman, B., \& Abbasi, A. S. (2014). Sexual Harassment at Workplace... A Case of Banking Sector in Lahore. Middle-East Journal of Scientific Research, 20 (5), 558-566. https://lahore.comsats.edu.pk/Papers/Abstracts/539-8587436721937900808.pdf

Page, T. E., \& Pina, A. (2015). Moral disengagement as a self regulatory process in sexual harassment perpetration at work: A preliminary conceptualization. Aggression and Violent Behavior, 21, 73-84. http://doi.org/10.1016/j.avb.2015.01.004

Quick, J. C., \& McFadyen, M. A. (2017). Sexual harassment: Have we made any progress? Journal of Occupational Health Psychology, 22(3). 286-289. https://doi.org/10.1037/ocp0000054

Qureshi, S. (2013). The emergence/extension of due diligence standard to assess the state response towards violence against women/domestic violence. South Asian Studies, 28 $(1)$, $55-66$.

http://journals.pu.edu.pk/journals/index.php/IJSAS/article/viewFile/2867/1113

Ramezani, R. (2015). Investigating the level and types of street harassment. Academic Journal of Psychological Studies, 4(4), 175-184.

Reuters (2018, June 26). Factbox: Which are the world's 10 most dangerous countries for women? https://www.reuters.com/article/us-women-dangerous-pollfactbox/factbox-which-are-the-worlds-10-most-dangerous-countries-for-womenidUSKBN1JM01Z

Sadruddin, M. M. (2013). Sexual harassment at workplace in Pakistan-Issues and remedies about the global issue at managerial sector. Journal of Managerial Sciences, 7(1), 113-125. https://ssrn.com/abstract $=2949467$

Salman, M., Abdullah, F., \& Saleem, A. (2016). Sexual harassment at workplace and its impact on employee turnover intentions. Business \& Economic Review, 8(1), 87-102. https://doi.org/10.22547/BER/8.1.6

Shams, S. (2018, November 25). Violence and harassment: South Asian women fight against patriarchy. https://www.dw.com/en/violenceand-harassment-south-asian-womenfight-against-patriarchy/a-46444410

Sigal, J., Gibbs, M. S., Goodrich, C., Rashid, T., Anjum, A., Hsu, D., \& Wei-Kang, P. (2005). Cross-cultural reactions to academic sexual harassment: Effects of individualist vs. collectivist culture and gender of participants. Sex Roles, 52(3/4), 201-215, http://doi.org/10.1007/s11199-005-1295-3

Social Policy and Development Center (SPDC). (2009). Social Development in Pakistan, Annual Review 2007-08. http://www.spdc.org.pk/Publications/Annual\%20Reviews/AR-9.pdf

Sojo, V. E., Wood, R. E., \& Genat, A. E. (2016). Harmful workplace experiences and women's occupational well-being: A meta-analysis. Psychology of Women Quarterly, 40(1), 10-40. http://doi.org/10.1177/0361684315599346 
Spencer, C., Mallory, A., Toews, M., Stith, S., \& Wood, L. (2017). Why sexual assault survivors do not report to universities: A feminist analysis. Family Relations Interdisciplinary Journal of Applied Family Studies, 66 (1), 166-179. https://doi.org/10.1111/fare.12241

Tariq, N., \& Kamal, A. (1997). Sexual harassment experience questionnaire for workplaces of pakistan: Development and validation. Pakistan Journal of Psychological Research, 12 (1-2), 1-20. http://www.pjprnip.edu.pk/index.php/pjpr/article/view/105

Thurston, R. C., Barinas-Mitchell, E., von Ka“nel, R., Chang, Y., Koenen, K. C., \& Matthews, K. A. (2017). Trauma exposure and endothelial function among midlife women. Menopause, 25(4), 368-374. http://doi.org/10.1097/GME.0000000000001036

Tov, W., \& Diener, Ed. (2013, January 10). Culture and subjective well-being. SSRN. http://dx.doi.org/10.2139/ssrn.2199219

Tsuladze, L., Chitashvili, M., Bendeliani, N., \& Arutinovi, L. (2013). Concept of happiness and happiness in georgia" perceptions and correlates of reported overall happiness. Tbilisi: Centre for Social http://css.ge/index.php?lang_id=ENG\&sec_id=23\&info_id=816 .

UN Women (2013). Prohibition of discrimination, harassment, including sexual harassment, and abuse of authority. United Nations (UN). https://www.un.org/womenwatch/uncoordination/antiharassment.html

Veenhoven, R. (2004). Happiness as a public policy aim: The greatest happiness principle. In P.A. Linley \& S. Joseph (Eds.). Positive psychology in practice (pp. 658-678). Wiley.

Yasmin, N. (2018). A study on reporting of sexual harassment by working women in LahorePakistan. FWU Journal of Social Sciences, 12(2), 24-34. http://sbbwu.edu.pk/journal/Winter_2018_Vol_12_\%20No_2/3.A_Study_on_Repor ting_of_Sexual_Harassment_by_Working_Women_in_Lahore_Pakistan.pdf

Yasmin, N., \& Jabeen, S. (2017). Workplace harassment: psychological effects and coping strategies in public and private organizations of Lahore-Pakistan. FWU Journal of Social Sciences, 11(1), 310-321. http://sbbwu.edu.pk/journal/WU_Journal_of_Social_Sciences_Summer_2017_Vol_ 11_No_1/28\%20Workplace\%20Harassment\%20Psychological\%20Effects.pdf

Zia, A., Batool, S., \& Yasin, Z. (2016). Women harassment at workplace: A study of Pakistani television channels. Global Media Journal: Pakistan Edition, 9 (1), 1-15. https://aiou.edu.pk/SAB/gmj/GMJ\%20Spring\%202016/Article_5.pdf 